\title{
CONHECIMENTOS DE DISCENTES DE ENFERMAGEM SOBRE VIOLÊNCIA SEXUAL CONTRA CRIANÇAS E ADOLESCENTES*
}

\author{
Júnia Aparecida Laia da Mata Fujita ${ }^{1}$, Tatiana Savoia Landini²
}

\begin{abstract}
RESUMO: A profissão da enfermagem, como fenômeno histórico, é influenciada pelas variáveis sociais, políticas e econômicas de cada época, estando sujeita às transformações em sua prática no decorrer do tempo. Diante das diversas transformações sociais que vêm ocorrendo ao longo dos últimos anos no Brasil, do acelerado processo de modernização científica e tecnológica que estamos sujeitos, somos impulsionados a protagonizar novas formas de conhecimento. Tais mudanças exigem posicionamento na área de formação profissional, que é desafiada a dar respostas, muitas vezes, às questões que emergem no campo social. Dentre os problemas emergentes no âmbito da saúde que tem exigido modificações na atuação profissional, focaliza-se, neste trabalho, a violência sexual contra crianças e adolescentes. Essa questão foi considerada, por muito tempo, apenas um problema social e não de saúde pública e, por isso, pouco tratada nos currículos dos cursos de graduação de Enfermagem. Nas últimas décadas, a violência ganhou maior visibilidade e se tornou um problema por diversos setores, dentre eles o da saúde. Objetivou-se por meio de deste estudo: a) analisar se o projeto pedagógico curricular da graduação de Enfermagem possibilita a formação do aluno para lidar com a violência sexual contra crianças e adolescentes na prática profissional; b) investigar os conhecimentos dos discentes do último semestre do curso de graduação de Enfermagem de uma instituição de ensino superior pública a respeito da violência sexual contra crianças e adolescentes. Tratou-se de uma pesquisa de campo, descritiva, exploratória, desenvolvida a partir de uma abordagem qualitativa. Selecionamos como cenário do estudo uma escola de Enfermagem que representa excelência na formação de enfermeiros no Brasil e que mantém seu currículo em constante discussão e transformação, de acordo com as demandas em saúde. Esperava-se encontrar no projeto pedagógico curricular da instituição traços de mudanças na formação profissional do enfermeiro para lidar com a violência sexual contra crianças e adolescentes. Para a efetivação da pesquisa, inicialmente, foi solicitada à direção do curso de graduação uma autorização, a qual foi concedida. O estudo também foi autorizado pelo Comitê de Ética e Pesquisa da Universidade, sob o protocolo 0779/10. O grupo de sujeitos da pesquisa foi composto por dois docentes do curso de graduação em Enfermagem que ministravam aulas nas disciplinas do Departamento de Pediatria e 26 discentes que estavam cursando o último semestre da graduação na instituição selecionada, no ano de 2010. Foram critérios de inclusão: alunos do último semestre da graduação em Enfermagem pesquisado e professores enfermeiros ministrantes de aulas sobre a temática da violência contra crianças e adolescentes em disciplinas do Departamento de Pediatria da escola de enfermagem. A produção dos dados consistiu de três etapas: análise do projeto pedagógico curricular do curso de graduação em Enfermagem da instituição participante do estudo; realização de entrevista com base no roteiro de perguntas discursivas aos professores que trabalham com a temática da violência contra crianças e adolescentes em disciplinas do Departamento de Pediatria; aplicação de entrevista aos alunos utilizando-se de um roteiro sobre conhecimentos e crenças acerca da violência sexual contra crianças e adolescentes. A coleta de dados foi realizada entre os meses de agosto e outubro do ano de 2010. Os participantes foram entrevistados de maneira confidencial e individual respeitando-se os preceitos éticos da Resolução 196/96 do Conselho Nacional de Saúde. Adotou-se a técnica de 'entrevista focalizada' com roteiros constituídos de perguntas discursivas. O tratamento dos dados foi realizado com base na Análise de Conteúdo e foram utilizados procedimentos sistemáticos e objetivos para descrever o conteúdo das mensagens, permitindo a produção de conhecimento a partir delas. Após a análise do projeto pedagógico curricular vigente no período da pesquisa, constatou-se que nenhuma das disciplinas da matriz curricular possuía em seu conteúdo programático, especificamente, o tema da violência sexual contra crianças e adolescentes. Apesar dessa temática não constar na matriz curricular, foram entrevistados os participantes da pesquisa a fim de verificar se em algum momento era abordado o assunto. A partir das entrevistas foram identificadas fragilidades na formação do enfermeiro, a saber: o déficit no tratamento do tema da violência e suas diversas expressões na graduação e a falta de estágios e práticas de campo na área de violência sexual. Desse modo, o objetivo de formar os alunos para lidar com problemas de saúde que emergem no campo social, como a violência sexual, proposto pela escola de enfermagem, não foi totalmente alcançado no ano de 2010. Os resultados obtidos a partir das entrevistas dos alunos representam os aspectos mais significativos em relação aos conhecimentos dos mesmos sobre o tema e sobre a formação do enfermeiro para lidar com esta questão. Não foram identificadas evidências de que os alunos possuíam formação científica para abordar sobre a temática da violência, contudo, percebeu-se que eles tinham familiaridade com o assunto. Muitos discentes atribuíram a outros profissionais o papel de lidar com a violência sexual contra crianças e adolescentes, principalmente, ao psicólogo e assistente social. Em nenhuma das respostas os participantes citaram como papel do enfermeiro notificar os casos suspeitos ou confirmados de violência sexual contra crianças ou adolescentes e demonstraram que desconheciam os procedimentos para a notificação, revelando uma situação preocupante que repercute no enfrentamento e manejo desse problema. Evidenciou-se a necessidade de delimitação do papel do enfermeiro diante da violência, por entidades representativas e pelo órgão que normatiza e regulamenta o exercício profissional, o Conselho Federal de Enfermagem, e de
\end{abstract}

Cogitare Enferm. 2012 Out/Dez; 17(4):784-5 
implantação de disciplinas e estágios na graduação que favoreçam a formação profissional na área. Diante dos resultados, não se pode negar que, atualmente, exista a necessidade de adequar o currículo do curso de Enfermagem incluindo o tema da violência. PALAVRAS - CHAVE: Violência sexual; Currículo; Educação em enfermagem; Enfermagem pediátrica; Adolescente.

*Resumo de dissertação apresentada ao Programa de Pós-Graduação em Educação e Saúde na Infância e na Adolescência da Universidade Federal de São Paulo - UNIFESP em 2011.

${ }^{1}$ Enfermeira. Mestre em Educação e Saúde na Infância e na Adolescência. Professora do Departamento de Enfermagem da Universidade Federal do Paraná.

${ }^{2}$ Socióloga. Doutora em Sociologia. Professora do Curso de Ciências Sociais da UNIFESP. Orientadora.

Autor correspondente:

Recebido: $14 / 06 / 2012$

Júnia Aparecida Laia da Mata Fujita

Aprovado: 08/08/2012

Universidade Federal do Paraná

Av. Presidente Affonso Camargo, 2125 - 80050-370 - Curitiba-PR-Brasil

E-mail: jumata.2905@gmail.com 